\title{
Postpartum Eclampsia- A Prospective Observational Hospital Based Study
}

\author{
Sukumar Mitra ${ }^{1}$, Seema Das ${ }^{2}$ \\ ${ }^{1}$ Department of Obstetrics and Gynaecology, Medical College, Kolkata, West Bengal, India. \\ ${ }^{2}$ Department of Obstetrics and Gynaecology, R. G. Kar Medical College, Kolkata, West Bengal, India.
}

\section{ABSTRACT}

\section{BACKGROUND}

The word eclampsia is derived from a Greek word eklampsis meaning 'sudden development'. It is one of the important causes of maternal mortality. This article focuses on the postpartum eclampsia which can occur in $25 \%$ of the cases of eclampsia. Though termination of pregnancy is said to be the ultimate cure of eclampsia, many patients develop eclamptic seizures after delivery of baby and placenta.

\section{METHODS}

A prospective observational study was carried out from July 2018 to June 2019 in a tertiary hospital, Medical College Kolkata. All women with postpartum eclampsia were included in the study after excluding any known cases of neurological disorders, space occupying lesions in brain and antepartum eclampsia.

\section{RESULTS}

Data was analysed using SPSS version and read as the percentage, mean median, maximum and minimum values. $98 \%$ of the cases were alive and only $2 \%$ succumbed to postpartum eclampsia. $92 \%$ had no focal neurological deficit. $82 \%$ of study sample had no history of antenatal hypertension indicating that normal blood pressure does not rule out eclampsia. The mean value of the blood parameters was within the normal range, indicating low value of such parameters to predict occurrence of postpartum eclampsia in the future.

\section{CONCLUSIONS}

Strict vigilant postpartum observation forms the cornerstone in reducing mortality from postpartum eclampsia till one can come up with better markers for prediction of such an event.

\section{KEY WORDS}

Postpartum Eclampsia, Post-Partum Observation, Prediction
Corresponding Author:

Seema Das,

Room No. 6. Ladies Hostel,

Above Fair Price Shop,

RG Kar Medical College \&

Hospital Campus, Kolkata,

West Bengal, India.

E-mail: cmadas0@gmail.com

DOI: $10.14260 / j e m d s / 2019 / 861$

Financial or Other Competing Interests: None.

How to Cite This Article:

Mitra S, Das S. Postpartum eclampsia- a prospective observational hospital based study. J. Evolution Med. Dent. Sci. 2019;8(52):3984-3988,

10.14260/jemds/2019/861

Submission 14-10-2019,

Peer Review 03-12-2019,

Acceptance 10-12-2019,

Published 30-12-2019.

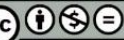




\section{BACKGROUND}

Eclampsia, which is considered a complication of severe preeclampsia, is commonly defined as new onset of grand mal seizure activity and/or unexplained coma during pregnancy or postpartum in a woman with signs or symptoms of preeclampsia.. ${ }^{[1,2]}$ In the fifth century, Hippocrates noted that headaches, convulsions, and drowsiness were ominous signs associated with pregnancy. In 1619, Varandaeus coined the term eclampsia in a treatise on gynaecology.[3,4] In the western world, the reported incidence of eclampsia is 1 in 2000 but in developing countries its incidence may be as high as 100 cases per 10,000 live birth. ${ }^{5}$ Pre-eclampsia is estimated to affect about $3-8 \%$ of deliveries while eclampsia affects about $1.4 \%$ of deliveries.[6] Based on initial results of WHO's Department of Reproductive Health and Research; the incidence of pre-eclampsia is estimated at $3.2 \%$ of live births, giving a total number of over 4 million cases each year, of which over 72,000 were fatal.[7] In India, the incidence of Eclampsia is reported to be $220 / 10,000$ deliveries. [7] Incidence of eclampsia varies inversely with the quality of antenatal care. It is estimated that about $10-15 \%$ of maternal mortality is associated with hypertensive disorders of pregnancy; particularly eclampsia. ${ }^{[8]}$ Hypertensive disorders of pregnancy are one of the most common causes of death in pregnancy.[9] They resulted in 46,900 deaths in 2015.[10] Around one percent of women with eclampsia die.[10]

Eclampsia is a life-threatening emergency that contributes a major cause of maternal morbidity and mortality. Traditionally it has been classified as ante, intra and postpartum according to time of appearance of convulsion and/or coma. Most cases of postpartum preeclampsia develop within 48 hours of childbirth is termed as early post-partum eclampsia. However, postpartum preeclampsia sometimes develops up to six weeks after childbirth. This is known as late postpartum preeclampsia.

Though the termination of pregnancy is said to be the ultimate cure of eclampsia, many a patient develop eclamptic seizures after delivery of baby and placenta, indicating a different clinical presentation and progress. Most cases of eclampsia present in the third trimester of pregnancy, with about $80 \%$ of eclamptic seizures occurring intrapartum or within the first 48 hours following delivery. Rare cases have been reported before 20 weeks' gestation or as late as 23 days' postpartum. Although there are numerous studies exploring ultrasound and biomarker prediction of patients at risk of pre-eclampsia, other than early detection of preeclampsia, no reliable test or symptom complex predicts the development of eclampsia. In developed countries, many reported cases have been classified as unpreventable. [11,12,13] Maternal risk factors used as criteria for severity classification by some international clinical practice guidelines do not accurately identify women at high risk of developing maternal complications [14]

There has been a marked reduction in the incidence of eclampsia in recent years, which may be attributed in part to improved prenatal care, including early detection of signs and symptoms of preeclampsia and prophylactic use of magnesium sulphate in the peripartum period.[15] However, there has been a shift toward an increased frequency of eclampsia in the postpartum period with most cases occurring in the late postpartum period.[16] This shift could be the result of the persistence and progression of preeclampsia that started during the intrapartum period or late manifesting disease after delivery but unrecognized before discharge. Because preeclampsia abates with placental delivery, obstetric units tend to discontinue seizure prophylaxis within 48 hours postpartum. However, up to $26 \%$ of eclamptic seizures occur beyond 48 hours and as late as 6 weeks after delivery.[17] These facts are consistent with a current theory on the pathogenesis of preeclampsia that suggests that the disease is caused by placental-related widespread endothelial cell dysfunction[18] as a result of increased circulating levels of antiangiogenic factors such as soluble truncated FMS-like tyrosine kinase-1 receptor isoform ${ }^{19}$ and soluble endoglin. ${ }^{20}$ Therefore, the onset of symptoms and signs of the disease may be dictated by the degree and time course of resolution of the endothelial damage. Indeed, Blaauw and collaborators demonstrated evidence of persistent endothelial dysfunction in a group of women with early onset preeclampsia up to 11 months after delivery.[21]

There is still paucity of sufficient data for postpartum eclampsia in medical literature. In the view of this our study envisages to study various demographic, clinical and biochemical factors in postpartum eclampsia.

\section{METHODS}

This prospective observational study was conducted in the Department of Obstetrics and Gynaecology, Eden Hospital, Medical College, Kolkata for 1 year from July 2018 to June 2019. Judging by the inclusion and exclusion criteria, all patients admitted with postpartum eclampsia in eclampsia unit of Eden hospital were included in the study. All postpartum eclampsia women admitted in eclampsia room of Eden building during the study period. The following were the exclusion criteria for this study-

A. Mothers with known neurological disease like epilepsy, meningitis, meningoencephalitis and other convulsive disorders.

B. Known cases of any neurological space occupying lesions.

C. Mothers who had preceding antenatal eclampsia. A purposive sampling was done.

\section{IEC Clearance}

Approved and informed consent availed.

\section{Laboratory Investigations}

A. Complete hemogram with platelet counts.

B. Liver function test- Aspartate Aminotransferase, Alanine Aminotransferase, Lactate dehydrogenase

C. Renal function test- Serum Uric Acid, Serum Urea, Serum Creatinine.

D. Blood Electrolytes- Serum Sodium and Serum Potassium.

\section{Statistical Analysis}

SPSS analysis (Version 2.0), Excel, Percentage. Mean, median, standard deviation, minimum and maximum value of the parameters observed were tabulated for the variables observed. 


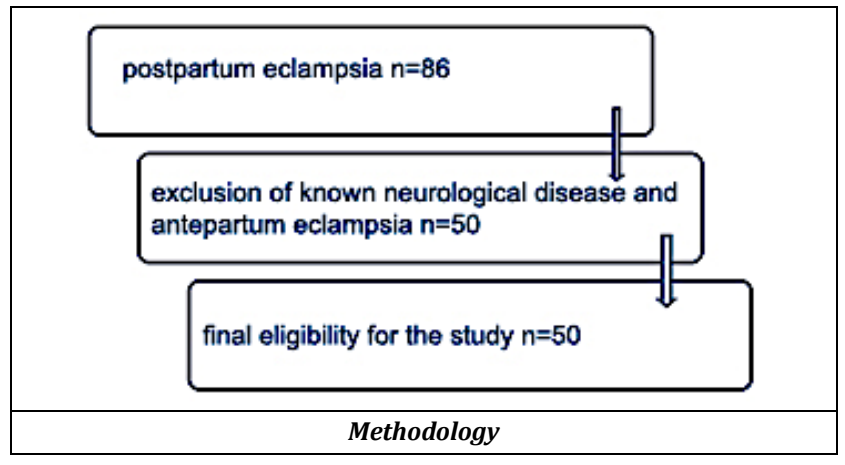

\section{RESULTS}

\begin{tabular}{|c|c|c|c|c|c|c|}
\hline Variable & No. & Mean & SD & Min & Max & Median \\
\hline SBP (mmHg) & 50 & 135.8 & 20 & 100 & 170 & 140 \\
\hline DBP (mmHg) & 50 & 86.68 & 13.47 & 60 & 120 & 90 \\
\hline Mean no. of convulsions & 50 & 1.52 & 1.52 & 1 & 9 & 1 \\
\hline Mean Glasgow coma scale & 50 & 13.54 & 1.43 & 10 & 15 & 14 \\
\hline Haemoglobin (g/dl) & 50 & 10.55 & 1.64 & 7 & 13.6 & 10.2 \\
\hline Mean platelet conc. (lacs/cumm) & 50 & 1.93 & 0.47 & 1.1 & 3 & 1.9 \\
\hline SGOT (IU/L) & 50 & 37.98 & 15.02 & 15.02 & 60 & 35 \\
\hline SGPT (IU/L) & 50 & 36.82 & 14.8 & 15 & 66 & 33.5 \\
\hline Urea (mg/dl) & 50 & 23.16 & 5.28 & 14 & 33 & 22 \\
\hline LDH (IU/L) & 50 & 268.52 & 133.57 & 113 & 314 & 215 \\
\hline Creatinine & 50 & 0.486 & 0.3 & 0.1 & 1 & 0.55 \\
\hline Uric acid (mg/dl) & 50 & 5.35 & 0.87 & 3.6 & 7.8 & 5.1 \\
\hline Serum Sodium (meq/L) & 50 & 133.9 & 3.85 & 129 & 146 & 132.5 \\
\hline Serum Potassium (meq/L) & 50 & 3.5 & 0.5 & 2.5 & 4.4 & 3.4 \\
\hline Table 1. Distribution of Mean of Various Parameters in \\
Postpartum Eclampsia \\
\hline
\end{tabular}

The mean systolic and diastolic blood pressure found among the 50 postpartum eclampsia patients were 135.8 $\mathrm{mmHg} \& 86.68 \mathrm{mmHg}$ respectively. Maximum no. of convulsions recorded was 9 with a mean of 1.52. Mean Glasgow coma scale was registered to be 13.54 with the minimum being 10. Mean Haemoglobin and platelet concentration were $10.55 \mathrm{gm} \%$ and $1.93 \mathrm{lacs} /$ cumm respectively. SGPT \& SGOT were maximum at about $60 \mathrm{IU} / \mathrm{L}$ $\& 66 \mathrm{IU} / \mathrm{L}$ each, with a mean within the normal range of $0-40$ $\mathrm{IU} / \mathrm{L}^{\#}$. LDH in most of the cases was raised with a mean of 268.52 IU/L and hit maximum at $314 \mathrm{IU} / \mathrm{L}$.

\begin{tabular}{|c|c|c|}
\hline Parameter & Category & Number (Percentage) \\
\hline \multirow{2}{*}{ Age } & $\leq 20$ & $36 \%$ \\
\cline { 2 - 3 } & $21-30$ yrs. & $54 \%$ \\
\hline \multirow{2}{*}{ Parity } & $\mathrm{P}_{0+0}$ & $58 \%$ \\
\cline { 2 - 3 } & Others & $42 \%$ \\
\hline \multirow{2}{*}{$\begin{array}{c}\text { Pre monitoring } \\
\text { Symptoms }\end{array}$} & Yes & $10 \%$ \\
\cline { 2 - 3 } $\begin{array}{c}\text { Previous antenatal } \\
\text { hypertension }\end{array}$ & No & $90 \%$ \\
\cline { 2 - 3 } & Yes & $18 \%$ \\
\hline \multirow{2}{*}{ Duration } & Early ${ }^{*}$ & $82 \%$ \\
\cline { 2 - 3 } & Late & $70 \%$ \\
\hline \multirow{2}{*}{ Focal neurological deficit } & Yes & $30 \%$ \\
\cline { 2 - 3 } & no & $8 \%$ \\
\hline \multirow{2}{*}{ Outcome } & Alive & $92 \%$ \\
\cline { 2 - 3 } & Death & $98 \%$ \\
\hline \multicolumn{2}{|c|}{ Table 2. Distribution of Various Clinical Parameters and Age } \\
\hline \multirow{2}{*}{}
\end{tabular}

Kidney Function Test apprised a mean urea and creatinine concentration to be around $23.16 \mathrm{mg} / \mathrm{dl}$ and creatinine $0.49 \mathrm{mg} / \mathrm{dl}$ respectively with maximum value to be $33 \mathrm{mg} / \mathrm{dl}$ and $1 \mathrm{mg} / \mathrm{dl}$ each. Mean serum uric acid level was above the normal cut off 4.5. The maximum serum uric acid level was $7.8 \mathrm{mg} / \mathrm{dl}$.

Both Serum Sodium and Potassium had mean level of $133.9 \mathrm{meq} / \mathrm{L}$ and $3.5 \mathrm{meq} / \mathrm{L}$ respectively and the minimum value reached to $129 \mathrm{meq} / \mathrm{L}$ and $2.5 \mathrm{meq} / \mathrm{L}$ each. $54 \%$ of the patients fall in the age group of $21-34$ yrs. and $58 \%$ of the patients had postpartum eclampsia were primigravida. $10 \%$ of the patients had premonitoring symptoms and the remaining $90 \%$ had no such complaints. $18 \%$ of the patients gave history of antenatal hypertension whereas the majority did not have any documented history of hypertension (82\%). Early postpartum eclampsia, defined as occurrence of convulsions within $48 \mathrm{hrs}$ postpartum comprised the maximum proportion (70\%) compared to late postpartum eclampsia accounting $30 \%$ of the cases of postpartum eclampsia. $92 \%$ cases had no focal neurological deficit whereas $8 \%$ had some deficit. Given the prognosis, $98 \%$ were alive and discharged subsequently to home and only $2 \%$ died after postpartum eclampsia, indicating overall good prognosis.

\section{DISCUSSION}

The natural progression of the disease is from symptomatic severe preeclampsia (Differentiated from preeclampsia by specific vital signs, symptoms, and laboratory abnormalities) to seizures. The current study which was conducted in Eden hospital, medical college Kolkata on the clinical presentation and the biochemical changes in post-partum eclamptic mothers showed a varied result than commonly believed. The change in Systolic blood pressure ranged from 100-170 mm of $\mathrm{Hg}$ and Diastolic blood pressure ranged from $60-120 \mathrm{~mm}$ of $\mathrm{Hg}$, which showed that even some normotensive mothers underwent post-partum eclampsia. All postpartum eclampsia patients became normotensive by 1 week of appearance of postpartum convulsion. The studied population did not show permanent neurological or cognitive dysfunction after recovery. The biochemical parameters which predicts the morbidity and mortality of eclamptic patients were found to be in absolute normal range; which showed that the post eclamptic mothers had no preponderance in developing HELLP syndrome. Although patients with severe preeclampsia are at greater risk for seizures, $25 \%$ of patients have symptoms consistent with mild preeclampsia (i.e., preeclampsia without severe features) before the seizures.

A study by Cooray et al found that the most common symptoms that immediately precede eclamptic seizures are neurologic symptoms (ie, headache, with or without visual disturbance), regardless of degree of hypertension. This suggests that closely monitoring patients with these symptoms may provide an early warning for eclampsia.[22,23]

The incidence of postpartum eclampsia is 0.9 per 1000 maternities in our study whereas in the study done by Kayem et al the incidence was very low (0.1 per 1000 maternities). In our study $10 \%$ had premonitory symptoms prior to seizure whereas in the study done by Chames et al the incidence of prodromal symptoms were very high.[24] Preeclampsia eclampsia syndrome is known to occur frequently in primi parous women who are exposed for the first time to the trophoblasts ${ }^{[25]}$ and in our study [Table 1] it has been correctly seen that $29(58.0 \%)$ patients were p0+0.

Recent years have shown an increased in the incidence of postpartum eclampsia probably due to better prenatal care and prophylactic use of $\mathrm{MgSO}_{4}$ in severe preeclampsia, 
Antepartum eclampsia and Intrapartum eclampsia. In a study by Chames et al, who found with improvement in antenatal care, early deduction of preeclampsia and prophylactic use of $\mathrm{MgSO}_{4}$, there has been increasing shift in the incidence of eclampsia towards the postpartum period. In our present study on postpartum eclampsia majority of them occurred within 48 hrs. of delivery (Early- 70\%)The ominous signs of eclampsia better referred to as the premonitory symptoms of eclampsia which is characterized by headaches, visual disturbances (Diminutions of vision, diplopia, scotoma etc.) and epigastric pain was not present in 45 (90\%) of the patients. So, premonitory symptoms were not so prevalent amongst postpartum eclamptic mothers. [Table 2] Although Chames MC et al found that 21 patients (91\%) with late postpartum eclampsia had 1 prodromal symptoms and 12 patients $(52 \%)$ had $>1$ symptom, 20 women $(87 \%)$ had headache, 10 women (44\%) had visual disturbances and 2 women (9\%) experienced epigastric pain.

The mean number of convulsion (mean \pm S.D.) of patients was $1.5200 \pm 1.5151$ (Range of 1.00- 9.00 and the median $1.00)$. Eventually we found that $41(82.0 \%)$ patients had no history of antenatal gestational hypertension and 9(18.0\%) had history of antenatal gestational hypertension; which indicated that postpartum eclampsia can even occur without any preceding antenatal gestational hypertension. [Table 2] The mean Glasgow coma scale [Table 2] (mean \pm S.D.) of patients was $13.5400 \pm 1.4316$ (Range 10.00-15.00 and the median Glasgow coma scale was 14.00) which hereby indicates that postpartum eclampsia was not associated with altered neurological status, this is possibly due to prompt initiation of anticonvulsive therapy. Focal neurological deficit which is characterized by sensory or motor deficit and impaired cognitive function which occurs in rare cases due to late intervention and management, was found in only 4 $(8.0 \%)$ of patients and $46(92.0 \%)$ were found to have no focal neurological deficit which concludes that there was no gross structural or physiological changes in the higher functions. The measurement of serum uric acid levels even though helps in diagnosis of preeclampsia and often considered as a marker and also used to predict maternal and fetal complications, was not found to be significantly raised in our study and the mean serum uric acid was between $5.3580 \pm 0.8707 \mathrm{mg} / \mathrm{dl}$.

The mean haemoglobin and liver enzymes were not abnormal in any of the patients. Mean Serum sodium and potassium levels were normal. Kidney function test w.r.t serum urea and creatinine were not deranged in any of the cases.

\section{CONCLUSIONS}

Post-partum eclampsia continues to be a challenge to predict. The fourth stage of labour should be observed carefully so as to implement timely interventions and avoid injuries due to fall. Moreover, it's important for the health care provider to include the possibility of occurrence of postpartum eclampsia during antenatal counseling. This will improve the awareness regarding institutional deliveries among the masses. Prognosis is excellent in a hospital setting if diagnosed earlier and anticonvulsants started. One of the important limitations of our study is that it does not compare the clinical and pathological variables within the normal population, which could have better helped in assessing the predictive value of each variable. Mode of delivery, duration of labour was not evaluated to find any association. Counseling and initiation of proper postpartum care form the pillars in reducing mortality due to postpartum eclampsia until a more reliable predictor is available.

\section{REFERENCES}

[1] Mattar F, Sibai BM. Eclampsia. VIII. Risk factors for maternal morbidity. Am J Obstet Gynecol 2000;182(2):307-12.

[2] Warrington JP. Placental ischemia increases seizure susceptibility and cerebrospinal fluid cytokines. Physiol Rep 2015;3(11):e12634.

[3] Gabbe. Obstetrics: normal and problem pregnancies. Hypertension. $\quad 5^{\text {th }}$ edn. Churchill Livingstone. An Imprint of Elsevier 2007.

[4] ACOG Committee on Obstetric Practice. ACOG practice bulletin. Diagnosis and management of preeclampsia and eclampsia. Number 33, Jan 2002. The American College of Obstetricians and Gynecologists. Int J Gynaecol Obstet 2002;77(1):67-75.

[5] Sharara HA. A review of eclampsia in Qatar: a twentyyear study (from January1991- December 2009). Qatar Med J 2013;2012(2):7-15.

[6] GBD 2015 Mortality and Causes of Death Collaborators. Global, regional and national life expectancy, all-cause mortality and cause-specific mortality for 249 causes of death, 1980-2015: a systematic analysis for the Global Burden of Disease Study 2015. Lancet 388(10053):1459544.

[7] Global Burden of Maternal Death and Disability, WHO, Geneva, Switzerland-2012 newsletter.

[8] Swain S, Ojha KN, Prakash A, et al. Maternal and perinatal mortality due to eclampsia. India Pediatr 1993;30(6):771-3.

[9] McDonald SD, Lutsiv O, Dzaja N, et al. A systematic review of maternal and infant outcomes following magnesium sulfate for pre-eclampsia/eclampsia in realworld use. International Journal of Gynaecology and Obstetrics 2012;118(2):90-6.

[10] WHO recommendations for prevention and treatment of pre-eclampsia and eclampsia. 2011.

[11] Fujita Y, Nakanishi TO, Sugitani M, et al. Placental elasticity as a new non-invasive predictive marker of pre-eclampsia. Ultrasound Med Biol 2019;45(1):93-7.

[12] Townsend R, Khalil A, Premakumar Y, et al. Prediction of pre-eclampsia: review of reviews. Ultrasound Obstet Gynecol 2019;54(1):16-27.

[13] Sepúlveda-Martínez A, Rencoret G, Silva MC, et al. First trimester screening for preterm and term pre-eclampsia by maternal characteristics and biophysical markers in a low-risk population. J Obstet Gynaecol Res 2019;45(1):104-12. 
[14] Menzies J, Magee LA, Macnab YC, et al. Current CHS and NHBPEP criteria for severe preeclampsia do not uniformly predict adverse maternal or perinatal outcomes, Hypertens Preg 2007;26(4):447-62.

[15] Lopez-Llera M. Main clinical types and subtypes of eclampsia. Am J Obstet Gynecol 1992;166(1 Pt 1):4-9.

[16] Chames MC, Livingston JC, Ivester TS, et al. Late postpartum eclampsia: a preventable disease? Am J Obstet Gynecol 2002;186(6):1174-7.

[17] Matthys LA, Coppage KH, Lambers DS, et al. Delayed postpartum preeclampsia: an experience of 151 cases. Am J Obstet Gynecol 2004;190(5):1464-6.

[18] Levine RJ, Maynard SE, Qian C, et al. Circulating angiogenic factors and the risk of preeclampsia. $\mathrm{N}$ Engl J Med 2004;350:672-83.

[19] Venkatesha S, Toporsian M, Lam C, et al. Soluble endoglin contributes to the pathogenesis of preeclampsia. Nat Med 2006;12(6):642-9.

[20] Roberts JM, Redman CW. Pre-eclampsia: more than pregnancy-induced hypertension. Lancet 1993;341(8858):1447-51.
[21] Blaauw J, Graaff R, van Pampus MG, et al. Abnormal endothelium-dependent microvascular reactivity in recently pre-eclamptic women. Obstet Gynecol 2005;105(3):626-32.

[22] Cooray SD, Edmonds SM, Tong S, et al. Characterization of symptoms immediately preceding eclampsia. Obstet Gynecol 2011;118(5):995-9.

[23] Kaur K, Shrivastav RD, Rahatgaonkar V, et al. Study of fetal and maternal outcome in eclampsia. International Journal of Recent Trends in Science and Technolgy 2014;11(1):42-4.

[24] Bamaniya A, Rajoria L, Nagar O, et al. A descriptive study of residual hypertension and biochemical changes following post-partum period of pre-eclampsia \& eclampsia presenting women. Sch J App Med Sci 2016;4(5E):1800-03.

[25] Bansal V, Damania KR. Hypertensive disorders of pregnancy. In: Amarnath B, Sabaratnam A, Kaizad RD, et al. eds. Arias practical guide to highrisk pregnancy and delivery. A South Asian Perspective. $4^{\text {th }}$ edn. New Delhi: Elsevier

2015. 